\title{
Phenotypical Expression of Maize Seedlings from Lines with the "Tallos Gemelos" Trait
}

\author{
Ma. Lorena Meraz-Fonseca, ${ }^{1}$ Ma. del Carmen Mendoza-Castillo, ${ }^{1}$ \\ Takeo Ángel Kato-Yamakake, ${ }^{1}$ and Adriana Delgado-Alvarado ${ }^{2}$ \\ ${ }^{1}$ Postgrado en Recursos Genéticos y Productividad-Genética, Colegio de Postgraduados, Campus Montecillo, \\ Km 36.5 Carretera México-Texcoco, 56230 Montecillo, MEX, Mexico \\ ${ }^{2}$ Colegio de Postgraduados, Campus Puebla, Boulevard Forjadores de Puebla No. 205, Santiago Momoxpan, \\ Municipio San Pedro Cholula Estado de Puebla, 72760 Puebla, PUE, Mexico \\ Correspondence should be addressed to Ma. del Carmen Mendoza-Castillo; camen@colpos.mx
}

Received 23 March 2015; Accepted 2 June 2015

Academic Editor: Karl H. Hasenstein

Copyright ( 2015 Ma. Lorena Meraz-Fonseca et al. This is an open access article distributed under the Creative Commons Attribution License, which permits unrestricted use, distribution, and reproduction in any medium, provided the original work is properly cited.

\begin{abstract}
In the Colegio de Postgraduados in Mexico, we have generated lines of maize (Zea mays L.) with the particularity that from a seed two or more stalks emerge and develop normally, calling that character "tallos gemelos." This trait possibly modifies the proportions of the constituent tissues of the seed and could increase the nutritional and nutraceutical quality of the grain. The aim of this study was to evaluate the germination percentage and quantify and describe the types of phenotypic expression of seedling with twin stalks in the lines. 100 seeds of each of the $26 \mathrm{~S}_{5}$ lines tested were used. At 15 days after planting in a greenhouse, the seedlings were classified based on their morphology. The results showed that, on average, the lines had $81.3 \%$ of emergence and $51 \%$ of twin stalks. Eight types of phenotypic expression in seedlings were identified and described with the character "tallos gemelos"; Type II showed the highest proportion (59.5\%). The phenotypical expressions identified in seedlings with the "tallos gemelos" trait are evidence of epigenetic mechanisms, since they present one of the features of epimutants, which is that they are reversible, that is; they can return to the original phenotype, in the present circumstance to normal plants (single stalk).
\end{abstract}

\section{Introduction}

During the course of evolution, angiosperms have evolved different reproduction systems and peculiar propagation types, as a consequence of their autotrophic mode of life. There are two forms of creating a new individual from seed: sexually (in which meiosis occurs) and asexually (in which there is no meiosis). Both processes can take place simultaneously. As a result of these processes, in the seed of some species or cultivars, several embryos are formed. This may originate from sexual or asexual inheritance. Traditionally, this phenomenon is called "polyembryony," which was discovered by Leeuwenhoek in 1719. He observed the appearance of two seedlings from the same citrus seed [1]. It was Strasburger [2], however, who demonstrated the nature of polyembryony in Citrus through extensive detailed study from a cytological and morphological perspective. Since then, polyembryony has been described in different plant taxa [3].

Spontaneous development of several embryos in one seed was described long ago by different researchers. They mention that the frequency of these embryos depends on the genotype and, normally, does not exceed $0.1 \%$ in a generation [4].

The occurrence of maize seeds with two embryos is an interesting biological phenomenon. Kiesselbach [5] identified cases in which the maize embryo had multiple plumules and primary roots with only one cotyledon, or scutellum. Because he did not find two independent embryos, but only one abnormal embryo, he called this condition "false polyembryony." Other authors describe maize seeds with two embryos, calling them polyembryonic seeds that give rise to twin seedlings [6]. In a study with 12 lines with 
different frequency of twin embryos (2-25\%), seeds of one or two embryos were compared and significant differences for nutritional and nutraceutical quality of seeds with twin embryos were found, as they increased 4 to $6 \%$ protein content, $21-34 \%$ lysine, and 3.5-13.6\% oil content [7].

The objective of this study was to determine the phenotypic behavior of maize lines that possess the "tallos gemelos" trait by obtaining the percentage of germination and frequency of seedlings with twin stalks and also to study, classify, and quantify the phenotypic expression of these seedlings.

\section{Materials and Methods}

Since 1992, the area of Plant Physiology of the Montecillo Campus of the Colegio de Postgraduados, State of Mexico $\left(19.52^{\circ} \mathrm{N}, 98.88 \mathrm{~W} ; 2,250 \mathrm{masl}\right)$, has been developing a maize project with the aim of incorporating the "tallos gemelos" trait (expressed as two identical plants growing from a single seed). This had been done by crossing a population that possesses this trait with three elite lines from the Program of Maize Improvement (1040, 1041, and 1053). Then from those crosses, by self-pollination and selection, $S_{5}$ inbred lines with two or more stalks were obtained.

For this study, maize seeds from $26 \mathrm{~S}_{5}$ lines that possess the "tallos gemelos" trait (TS) were used; these lines are highly vigorous and produce more than 50\% twin stalk seedlings. The batch of seeds used for the germination assay was obtained during the 2011 spring-summer by fraternal pollinations.

The "tallos gemelos" lines were classified in groups based on their original lines (1040G, 1041G, and 1053G) and on the frequency of twin stalks. A high frequency line (HFG) had more than $46 \%$ twin stalk plants and a low frequency group (LFG) had seeds producing less than $45.5 \%$ twin stalk plants. In this way, 14 high frequency and 12 low frequency "tallos gemelos" lines were obtained.

The study was conducted in a greenhouse in 2012, at the Montecillo Campus, Colegio de Postgraduados. For efficient data collection, ten sowing dates were planned to cover the study of seedlings from the 26 lines. Seeds were sown in plastic 128 -cavity trays with peat moss substrate. One seed was planted in each cavity and 100 seeds per treatment were established. Planted trays were watered daily in the morning with a manual sprinkler for the 15 days defined for seedling growth.

At the end of the time established for seedling growth (15 days after sowing), the following variables were recorded. Emerged seedlings (\%): the total number of emerged seedlings per line was counted and divided by 100. A seedling was considered emerged when the plumule was visible; $100 \%$ was considered the maximum percentage of germination. Seedlings with tallos gemelos (\%): the percentage of seedling with tallos gemelos per line was calculated considering only the total number of emerged seedlings. A twin stalk seedling was one that had two or more stalks growing from a single seed. Classification of twin stalk seedling phenotypes: each of the seedlings was observed, photographed, and classified on the basis of its morphology. Once classified, each type of expression was described and the number of seedlings of each phenotype present in each line was recorded. For analysis of emergence and twin stalk seedlings percentages, frequency tables were constructed using percentage intervals. The results are presented by line number and frequency relative to the total number of lines.

\section{Results and Discussion}

The percentage of emerged seedlings of the lines with the "tallos gemelos" trait fluctuated between 42 and 96\%. Half of the 26 lines studied had emergence percentages above $85 \%$. Of these, seven belong to group 1040G, and of these 2446, 2454, and 2460 were HFG and 2455, 2456, 2457, and 2458 were LFG. Three lines belong to group 1041G (2466, HFG, and 2467 and 2468, LFG); the rest were in group 1053G (2470 and 2473, HFG, and 2472, LFG) (Table 1).

The lines with the highest percentages of emergence were 2468 of group $1041 \mathrm{G}$ and 2473 of group $1053 \mathrm{G}$, both with $96 \%$. The lowest percentage was recorded for line 2459 of group $1040 \mathrm{G}$ with $42 \%$.

Emergence was analyzed within each group of lines, and the highest percentage was found in 1053G, 89\%. Group $1040 \mathrm{G}$ had $79 \%$, and the lowest percentage was in group $1041 \mathrm{G}$ with $76 \%$. The overall average emergence of the 26 lines, relative to the number of seeds planted, was acceptable $(81.3 \%)$. This test is important since it is directly related to seed and seedling vigor. Willenborga et al. [8] point out that identification of genotypes with high germination and emergence percentages can help to improve seedling vigor, establishment in the field, and intraspecific competitiveness.

The number of high frequency "tallos gemelos" lines (HFG) increased from the 14 recorded under field conditions (Montecillo, 2011) to 16 in a greenhouse (Montecillo, 2012). These 16 lines exhibited percentages above 46\% (HFG) and accounted for $62 \%$ of all the lines studied. The remaining $38 \%$ had percentages of twin stalk seedlings below $45.5 \%$ (LFG). By group, group $1041 \mathrm{G}$ was found to have the highest percentage of twin stalk seedlings (61\%), followed by group $1040 \mathrm{G}$ with $49 \%$ and group $1053 \mathrm{G}$ with $46 \%$ (Table 2).

Four lines of group 1040G (2449, 2450, 2451, and 2461), three of group $1041 \mathrm{G}(2463,2464$, and 2468), and one of group 1053G (2470) had frequencies of "tallos gemelos" above $60 \%$ (Table 2 ). This suggests that there are differences in how this trait is incorporated and these depend directly on their population of origin.

On average, the 26 lines under study had 51\% twin stalk seedlings. These data are significantly higher than those reported by Pérez [9] (personal communication, 2004), as the result of the assessment of previous versions of these lines (families of the same "tallos gemelos" maize populations in the High Valleys). He found a percentage below 2\% of the assessed seeds with two or more embryos. The increase in the percentage of twin stalk seedlings obtained in our study is important since it highlights the positive effect of the genetic improvement methods used to increase the percentage of "tallos gemelos." These methods were selfing for the formation of lines and their selection over generations. These results agree with those reported by Espinoza et al. [10], who increased the frequency of "twin plants" from $1.5 \%$ in 
TABLE 1: Frequency and number of lines with the "tallos gemelos" trait, percentage of emerged seedlings grown in a greenhouse.

\begin{tabular}{|c|c|c|c|c|c|c|c|c|c|c|c|c|c|c|}
\hline \multirow{4}{*}{$\begin{array}{l}\text { Emergence } \\
(\%)\end{array}$} & \multicolumn{2}{|c|}{ Lines } & \multicolumn{12}{|c|}{ Group of lines } \\
\hline & \multirow{3}{*}{ Number } & \multirow{3}{*}{ Frequency } & \multicolumn{6}{|c|}{ Number } & \multicolumn{6}{|c|}{ Frequency } \\
\hline & & & \multicolumn{2}{|c|}{$1040 \mathrm{G}$} & \multicolumn{2}{|c|}{$1041 \mathrm{G}$} & \multicolumn{2}{|c|}{$1053 \mathrm{G}$} & \multicolumn{2}{|c|}{$1040 \mathrm{G}$} & \multicolumn{2}{|c|}{$1041 \mathrm{G}$} & \multicolumn{2}{|c|}{$1053 \mathrm{G}$} \\
\hline & & & HFG & LFG & HFG & LFG & HFG & LFG & HFG & LFG & HFG & LFG & HFG & LFG \\
\hline$>85$ & 13 & 0.50 & 3 & 4 & 1 & 2 & 2 & 1 & 0.19 & 0.25 & 0.17 & 0.33 & 0.50 & 0.25 \\
\hline $70-84.5$ & 6 & 0.23 & 3 & 2 & 0 & 0 & 0 & 1 & 0.19 & 0.12 & 0.0 & 0.00 & 0.0 & 0.25 \\
\hline$<70$ & 7 & 0.27 & 3 & 1 & 0 & 3 & 0 & 0 & 0.19 & 0.06 & 0.0 & 0.50 & 0.00 & 0.00 \\
\hline Total & 26 & 1.00 & 9 & 7 & 1 & 5 & 2 & 2 & 0.57 & 0.43 & 0.17 & 0.83 & 0.50 & 0.50 \\
\hline
\end{tabular}

HFG = high frequency group, selected for high frequency of "tallos gemelos" seedlings ( $>46 \%)$; LFG = low frequency group, selected for low frequency of seedling with twin stalks $(<45.5 \%)$.

TABLE 2: Number and frequency of lines with the "tallos gemelos" trait, relative to the proportion of twin stalk seedlings.

\begin{tabular}{lccccccccc}
\hline Interval $^{*}$ & \multicolumn{4}{c}{ Number } & \multicolumn{5}{c}{ Frequency } \\
& 1040G & 1041G & 1053G & Total & 1040G & $1041 G$ & $105 G$ & Total \\
\hline$>60$ & 4 & 3 & 1 & 8 & 0.15 & 0.11 & 0.04 & 0.31 \\
$46-59.5$ & 5 & 2 & 1 & 8 & 0.19 & 0.08 & 0.04 & 0.31 \\
$35-45.5$ & 6 & 0 & 0 & 6 & 0.23 & 0.00 & 0.00 & 0.23 \\
$<34.5$ & 1 & 1 & 2 & 4 & 0.04 & 0.04 & 0.08 & 0.15 \\
Total & 16 & 6 & 4 & 26 & 0.61 & 0.23 & 0.16 & 1.00 \\
\hline
\end{tabular}

${ }^{*}$ Percentage intervals of twin stalk seedlings.

the original population to $47 \%$ in the sixth selection cycle through recurrent selection. Erdelská and Vidovencová [4] indicate that it is possible to increase the frequency of seeds with two embryos, and this is achieved through continuous selection of hybrids and other materials.

3.1. Phenotypic Expression of Seedlings from Lines with the Twin Stalk Trait. Through counting and classifying 15-dayold seedlings, different forms of phenotypic expression were identified. Of all the seedlings from the 26 lines with the "tallos gemelos" trait grown in the greenhouse, 49\% had a single stalk (Type I, seedlings with no twin) and the other $51 \%$ were twin stalk seedlings. Furthermore, among all of the twin stalk seedlings, regardless of their origin or line group, seven different types of seedling expression (Types II-VIII) were found. These are described in the following.

\subsection{Seedlings with No Twin}

3.2.1. Type I. This seedling has a single stalk. Normal morphology is seen in all of its structures: radicle, seminal roots, adventitious roots, mesocotyl (long and thin), stalk axis, and coleoptile (covering that protects the plumules during emergence); also the first and second ligulate leaves are exhibited (Figure 1, Type I).

\subsection{Twin Seedlings}

3.3.1. Type II. This seedling has twin stalks growing from a single seed. There are two stem axes with two independent coleoptiles; stem bifurcation is distinguished at the coleoptile node. The two stalks share the mesocotyl (short and thick) and the root system is complete, normal in appearance with a single radicle (Figure 1, Type II). This type of expression was exhibited in $59.5 \%$ of all the twin stalk seedlings detected in this study.

3.3.2. Type III. This seedling has fused twin stalks that share the root system as well as the mesocotyl, which is short and thick. The coleoptile is normal and the axis is seen as a single stalk up to the first leaf (the two primary leaves are joined giving the impression of being a single leaf). From the upper internode to the first leaf, the stalk begins to bifurcate (Figure 1, Type III). This type of seedling had a frequency of $26 \%$ of all twin stalk seedlings.

3.3.3. Type $I V$. This seedling has twin stalks that share a single radicle. Its mesocotyl (short and thick) and coleoptile are normal. The stem axes separate at the upper internode to the coleoptile node, and the aerial part is rosette shaped (brachytic seedling) (Figure 1, Type IV). This type appeared in $12.1 \%$ of all the twin stalk seedlings studied.

3.3.4. Type $V$. Two independent seedlings are observed at germination; it seems that the embryo divides early in its development. These seedlings have two stalks, two root systems with their respective radicles, and seminal roots. They are joined at the scutellum node (Figure 1, Type V). This type is seen in only $1.5 \%$ of the cases.

3.3.5. Type VI. This seedling has independent twin stalks, having two mesocotyls, two coleoptiles, and two plumules but sharing the same radicle. It is possible that differentiation of the independent axes occurred at a very early stage of embryo development (Figure 1, Type VI). Of all the twin stalk seedlings of the 26 lines assessed, this type constituted $0.4 \%$.

3.3.6. Type VII. These seedlings have three (Figure 1, Type VII $\alpha$ ) and four (Figure 1, Type VII $\beta$ ) independent stalks that share the mesocotyl (short and thick) and the coleoptile (normal). The stalks separate at the coleoptile node. They also have two independent radicles. The percentage of this seedling type was $0.4 \%$. 



S: stalk
R: radicle
M: mesocotyl
F: fused radicles
C: coleoptile

FIGURE 1: Maize seedlings from lines with the "tallos gemelos" (TS) trait. Type I: normal seedling; all its structures can be seen. Type II: TS seedling with independent axes and normal aerial part. Type III: TS seedlings that share radicle, mesocotyl, and coleoptile, giving the impression of a single stalk. Type IV: TS seedling with rosette-shaped aerial part and one radicle. Type $V$ : TS seedling with independent axes and fused radicles. Type VI: TS seedling with independent axes that share a radicle. Type VII: seedling with three $(\alpha)$ and four stalks $(\beta)$ that share mesocotyl and coleoptile but have two separate radicles. Type VIII: seedling with three stalks and three fused radicles.

3.3.7. Type VIII. These seedlings have three independent stalks that share the mesocotyl (thick) and the coleoptile (normal). Separation of these seedlings begins at the coleoptile node. They also have three radicles fused at their base (Figure 1, Type VIII). This seedling type was the least frequent $(0.1 \%)$.

In general, the percentage of seedlings with two or more radicles in the 26 lines studied was less than $1 \%$, contrasting with Espinoza-Velázquez et al. [11] who reported an average of
$14 \%$ seedlings with multiple radicles in their polyembryonic genotypes.

Of the different phenotypic expressions found in seedlings of the "tallos gemelos" lines studied, it seems that all are from a single embryo that originates from the fusion of gametes. This suggests that in these genetic materials changes occur at different stages of development of the sexual embryo that result in the phenotypical expression of the seedlings described here, and because of their morphology, it is 
believed that they are not embryos that grow from somatic tissues or from asexual reproduction. Erdelská [12], who studied polyembryony in maize with histological analyses, reports three main types of expression. (1) Twin embryos originating from several embryonic sacs, generally located on opposite sides or separated places of the seed; they do not have common tissues and germination is independent. (2) Twin or triplet embryos formed from individual cells originating from the egg cell, or from several closely packed ovules separated by epidermal layers; they have a common endosperm and the plumules and radicles are independent. (3) Polyembryony caused by early cell division of the embryo; this may be spontaneous or induced. The embryos share a common suspensor, part of the scutellum, and the superficial layers of the radicle, so that when the seed germinates, the seedling has a root complex and separate plumules. In our study, the twin stalk seedlings identified coincide with Type 3 of the classification proposed by Erdelská [12], specifically Types II, IV, V, VI, and VIII. These types had in common the characteristics of two independent axes (separate plumules) and a single root system.

Histological analyses permit distinguishing different types of polyembryony in maize seeds, enabling us to relate twin or triplet seedlings to their origin. These crucial differences are associated with the location of the embryos in the seed, the structure of the embryos, mainly the presence or absence of some common tissues or cells, and the type of germination [12].

To obtain the lines to be studied, selfing and increased sib crosses were performed with seed from twin stalk plants. However, normal seedlings (one stalk, $49 \%$ on average) were always segregated from twin stalk seedlings (51\% on average).

The phenotypical expressions identified in seedlings with the "tallos gemelos" trait are evidence of epigenetic mechanisms present in these lines since one of the features of epimutants is that they are reversible; that is, they can return to the original phenotype, in the present case, to normal plant with single stalk morphology. The data suggest that DNA sequence controlling the trait did not change with the modification of diverse phenotypes expressions (Table 2 and Figure 1). Therefore, the tallos gemelos trait seems to be a suitable model for future studies of these mechanisms for obtaining further knowledge about plant molecular developmental processes. Epigenetic modifications are described as an inheritable change in phenotype that does not involve DNA mutation $[13,14]$.

3.4. Phenotypic Expression of "Tallos Gemelos" in the Line Groups. In group 1040G, Type II was the most frequent phenotypic expression of the twin stalk seedlings, fluctuating between 50 and $83 \%$. Type III appeared in only two lines (2447 and 2458) with percentages of $50 \%$ and $58 \%$, respectively. Half of the lines of group $1041 \mathrm{G}$ had between 40 and $68 \%$ Type II seedlings, while the other half had Type III twin stalk seedlings. In group $1053 \mathrm{G}$, all of the lines exhibited Type II twin stalk seedlings, fluctuating between $54 \%$ and $77 \%$ (Table 3).

In general, of the entire twin stalk seedlings obtained from the 26 lines studied, the type of expression that was most
TABLE 3: Frequency at which types of phenotypic expression occur in the 26 maize lines with the "tallos gemelos" trait. Montecillo, Texcoco, State of Mexico.

\begin{tabular}{lcccccccc}
\hline \multirow{3}{*}{ Group } & Line & \multicolumn{8}{c}{ Twin stalk seedling types } \\
& & II & III & IV & V & VI & VII & VIII \\
\hline $1040 \mathrm{G}$ & 2446 & 0.66 & 0.14 & 0.20 & 0.00 & 0.00 & 0.00 & 0.00 \\
$1040 \mathrm{G}$ & 2447 & 0.39 & 0.50 & 0.11 & 0.00 & 0.00 & 0.00 & 0.00 \\
$1040 \mathrm{G}$ & 2448 & 0.67 & 0.22 & 0.11 & 0.00 & 0.00 & 0.00 & 0.00 \\
$1040 \mathrm{G}$ & 2449 & 0.82 & 0.03 & 0.13 & 0.02 & 0.00 & 0.00 & 0.00 \\
$1040 \mathrm{G}$ & 2450 & 0.83 & 0.11 & 0.06 & 0.00 & 0.00 & 0.00 & 0.00 \\
$1040 \mathrm{G}$ & 2451 & 0.59 & 0.24 & 0.17 & 0.00 & 0.00 & 0.00 & 0.00 \\
$1040 \mathrm{G}$ & 2452 & 0.73 & 0.27 & 0.00 & 0.00 & 0.00 & 0.00 & 0.00 \\
$1040 \mathrm{G}$ & 2453 & 0.69 & 0.31 & 0.00 & 0.00 & 0.00 & 0.00 & 0.00 \\
$1040 \mathrm{G}$ & 2454 & 0.67 & 0.20 & 0.13 & 0.00 & 0.00 & 0.00 & 0.00 \\
$1040 \mathrm{G}$ & 2455 & 0.53 & 0.29 & 0.18 & 0.00 & 0.00 & 0.00 & 0.00 \\
$1040 \mathrm{G}$ & 2456 & 0.68 & 0.16 & 0.16 & 0.00 & 0.00 & 0.00 & 0.00 \\
$1040 \mathrm{G}$ & 2457 & 0.51 & 0.11 & 0.34 & 0.02 & 0.02 & 0.00 & 0.00 \\
$1040 \mathrm{G}$ & 2458 & 0.34 & 0.58 & 0.05 & 0.00 & 0.03 & 0.00 & 0.00 \\
$1040 \mathrm{G}$ & 2459 & 0.50 & 0.44 & 0.06 & 0.00 & 0.00 & 0.00 & 0.00 \\
$1040 \mathrm{G}$ & 2460 & 0.69 & 0.31 & 0.00 & 0.00 & 0.00 & 0.00 & 0.00 \\
$1040 \mathrm{G}$ & 2461 & 0.56 & 0.33 & 0.00 & 0.05 & 0.05 & 0.00 & 0.00 \\
$1041 \mathrm{G}$ & 2463 & 0.27 & 0.53 & 0.16 & 0.02 & 0.00 & 0.02 & 0.00 \\
$1041 \mathrm{G}$ & 2464 & 0.68 & 0.25 & 0.07 & 0.00 & 0.00 & 0.00 & 0.00 \\
$1041 \mathrm{G}$ & 2465 & 0.54 & 0.46 & 0.00 & 0.00 & 0.00 & 0.00 & 0.00 \\
$1041 \mathrm{G}$ & 2466 & 0.25 & 0.47 & 0.27 & 0.00 & 0.00 & 0.00 & 0.00 \\
$1041 \mathrm{G}$ & 2467 & 0.33 & 0.67 & 0.00 & 0.00 & 0.00 & 0.00 & 0.00 \\
$1041 \mathrm{G}$ & 2468 & 0.41 & 0.22 & 0.11 & 0.24 & 0.00 & 0.00 & 0.03 \\
$1053 \mathrm{G}$ & 2470 & 0.77 & 0.07 & 0.13 & 0.03 & 0.00 & 0.00 & 0.00 \\
$1053 \mathrm{G}$ & 2471 & 0.55 & 0.27 & 0.14 & 0.05 & 0.00 & 0.00 & 0.00 \\
$1053 \mathrm{G}$ & 2472 & 0.69 & 0.24 & 0.07 & 0.00 & 0.00 & 0.00 & 0.00 \\
$1053 \mathrm{G}$ & 2473 & 0.54 & 0.32 & 0.14 & 0.00 & 0.00 & 0.00 & 0.00 \\
\hline
\end{tabular}

The description of the types of phenotypic expression of the seedlings is found in Figure 1 of this paper.

frequent was Type II (59.5\%), followed by Type III with $26 \%$, Type IV with $12.1 \%$, Type V with $1.5 \%$, Type VI with $0.4 \%$, Type VII with $0.4 \%$, and Type VIII with $0.1 \%$ (Figure 2 ). It is important to mention that Type $\mathrm{V}$ was present at a higher frequency in group 1041G, while Types VII and VIII only appeared in group $1041 \mathrm{G}$ and Type VI was observed only in group $1040 \mathrm{G}$ (Table 3).

In most of the seedlings with "twin stalks" Type IV, the presence of mesocotyls and short and thick internodes were observed; this was due to the merging of the two stems, giving the appearance of a brachysm stalk (dwarf stalk); when these plants continue the development into mature plants, some of them might express abnormal or square stem phenotypes [6]. Meanwhile, seedlings of "twin stalks" of Types II and III and of the single stalks (not twins) have longer internodes and are phenotypically of normal appearance.

Pérez (personal communication, 2004) identified two types of seedlings growing from a single seed, and his description coincides with a normal type (without twin) and with Type II, with two stalks per seed, which he classified in turn as (a) seedlings with two axes in a single coleoptile and 


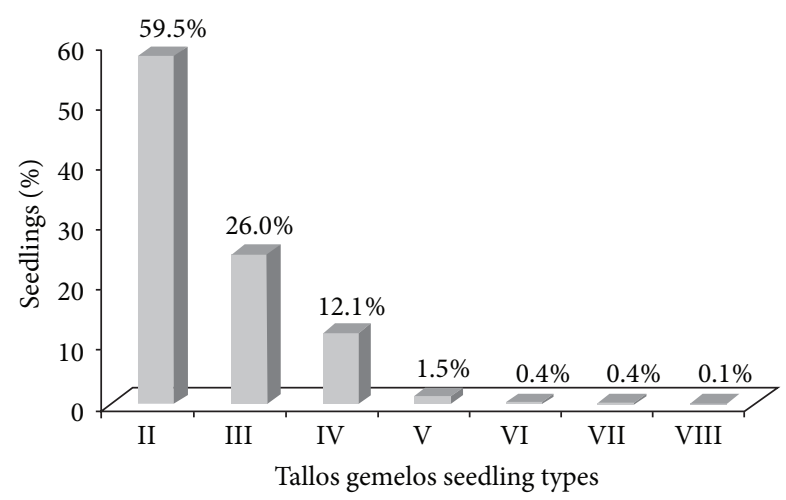

FIGURE 2: Percentage of twin stalk seedling types from 26 maize lines with the "tallos gemelos" trait, based on the classification described in Figure 1 of this paper.

(b) seedlings with two totally independent axes that share the mesocotyl and root system.

\section{Conclusions}

On average, the "tallos gemelos" maize lines had a high percentage of emergence (81.3\%) and of twin stalks (51\%), confirming that the genetic improvement process used has been favorable in obtaining vigorous lines with high expression of the trait.

In the 26 lines studied, eight types of seedling phenotypic expression were identified, $49 \%$ had a single stalk (Type I, seedlings without a twin), and the other $51 \%$ were twin stalk seedlings (Types II-VIII). Of the seedlings with twin stalks, Type II was that which occurred in the highest percentage (59.5\%).

The "tallos gemelos" trait is proposed as an epigenetic model for future studies of diverse nature.

\section{Conflict of Interests}

The authors declare that there is no conflict of interests regarding the publication of this paper.

\section{References}

[1] T. B. Batygina and G. Y. Vinogradova, "Phenomenon of polyembryony. Genetic heterogeneity of seeds," Russian Journal of Developmental Biology, vol. 38, no. 3, pp. 126-151, 2007.

[2] E. Strasburger, "Üeber polyembryonie," Jenaische Zeitschrift für Naturwissenschaft, vol. 12, pp. 647-670, 1878.

[3] K. K. Lakshmanan and K. B. Ambegaokar, "Polyembryony," in Embryology of Angiosperms, B. M. Johri, Ed., pp. 445-474, Springer, Berlin, Germany, 1984.

[4] O. Erdelská and Z. Vidovencová, "Cleavage polyembryony in maize," Sexual Plant Reproduction, vol. 5, no. 3, pp. 224-226, 1992.

[5] T. A. Kiesselbach, "False Polyembryony in maize," The American Journal of Botany, vol. 13, no. 1, pp. 33-34, 1926.

[6] G. M. Castro and S. Rodríguez, "Estudio preliminar del potencial de plantas de maíz con tallos gemelos," Fitotecnia, vol. 2, no. 3, pp. 39-49, 1979.
[7] N. Pešev, R. Petrović, L. Zečević, and M. Milošević, "Study of possibility in raising maize inbred lines with two embryos," Theoretical and Applied Genetics, vol. 47, no. 4, pp. 197-201, 1976.

[8] C. J. Willenborga, J. C. Wildemanc, A. K. Millerb, B. G. Rossnageld, and S. J. Shirtliffeb, "Oat germination characteristics differ among genotypes, seed sizes, and osmotic potentials," Crop Science, vol. 45, no. 5, pp. 2023-2029, 2005.

[9] D. J. Pérez, Comparación morfológica y agronómica de plantas gemelas y no gemelas de poblaciones de maíz de Valles Altos [M.S. thesis], Colegio de Postgraduados, Texcoco, Mexico, 2004.

[10] J. Espinoza, M. C. Vega, E. Navarro, and G. A. Burciaga, "Poliembrionía en maíces de porte normal y enano," Agronomía Mesoamericana, vol. 9, no. 2, pp. 83-88, 1998.

[11] J. Espinoza-Velázquez, J. Valdés-Reyna, and J. M. AlcaláRodríguez, "Morfología y anatomía de radículas múltiples en plántulas de maíz derivadas de cariopsis con poliembrionía," Polibotánica, vol. 33, pp. 207-221, 2012.

[12] O. Erdelská, "Polyembryony in maize : histological analysis," Acta Societatis Botanicorum Poloniae, vol. 65, no. 1-2, pp. 123125, 1996.

[13] D. E. Gottschling, "Epigenetics: from phenomenon to field," in Epigenetics, C. D. Allis, T. Jenuwein, and D. Reinberg, Eds., pp. 1-13, Cold Spring Harbor Laboratory Press, Cold Spring Harbor, NY, USA, 2007.

[14] A. D. Goldberg, C. D. Allis, and E. Bernstein, "Epigenetics: a landscape takes shape," Cell, vol. 128, no. 4, pp. 635-638, 2007. 

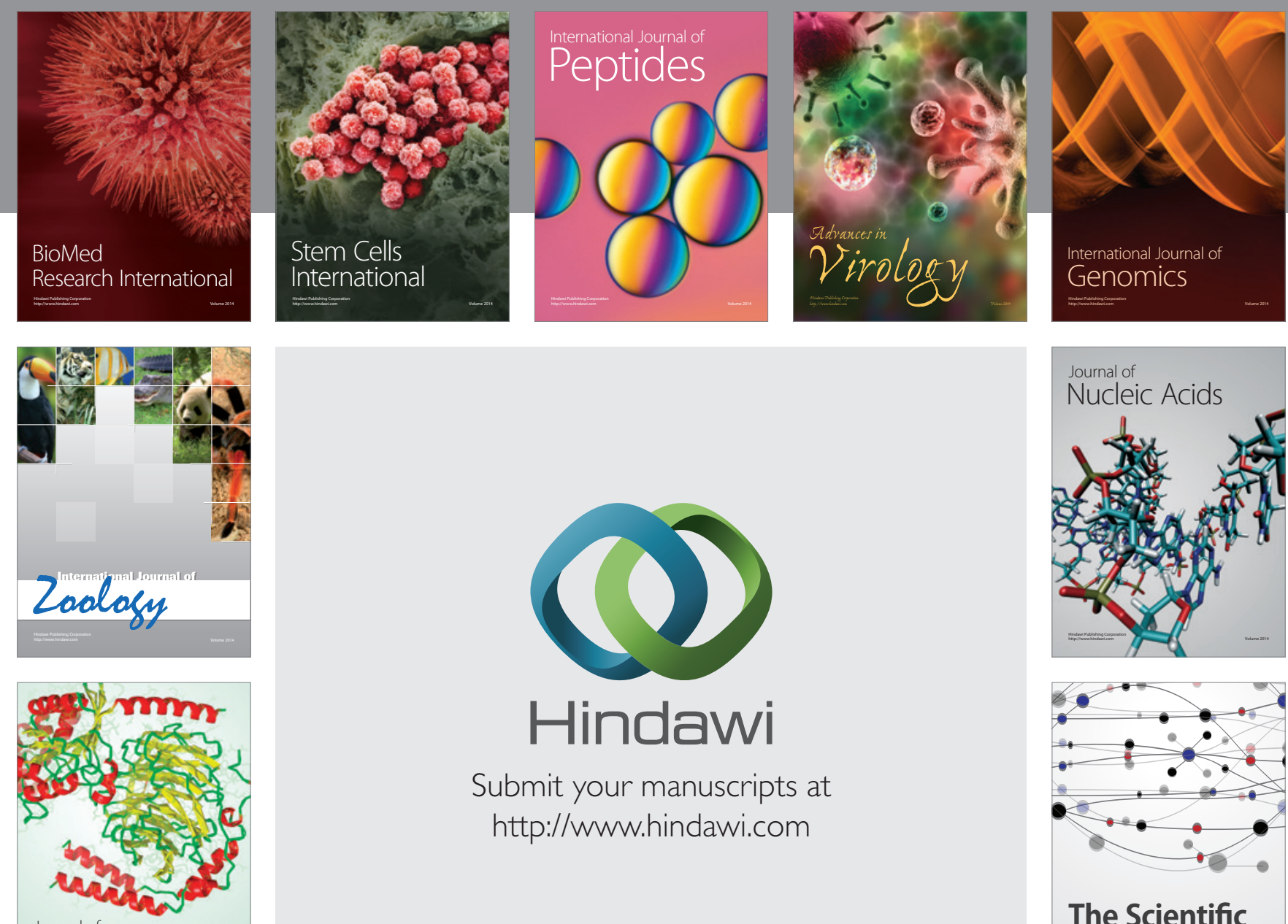

Submit your manuscripts at

http://www.hindawi.com

Journal of
Signal Transduction
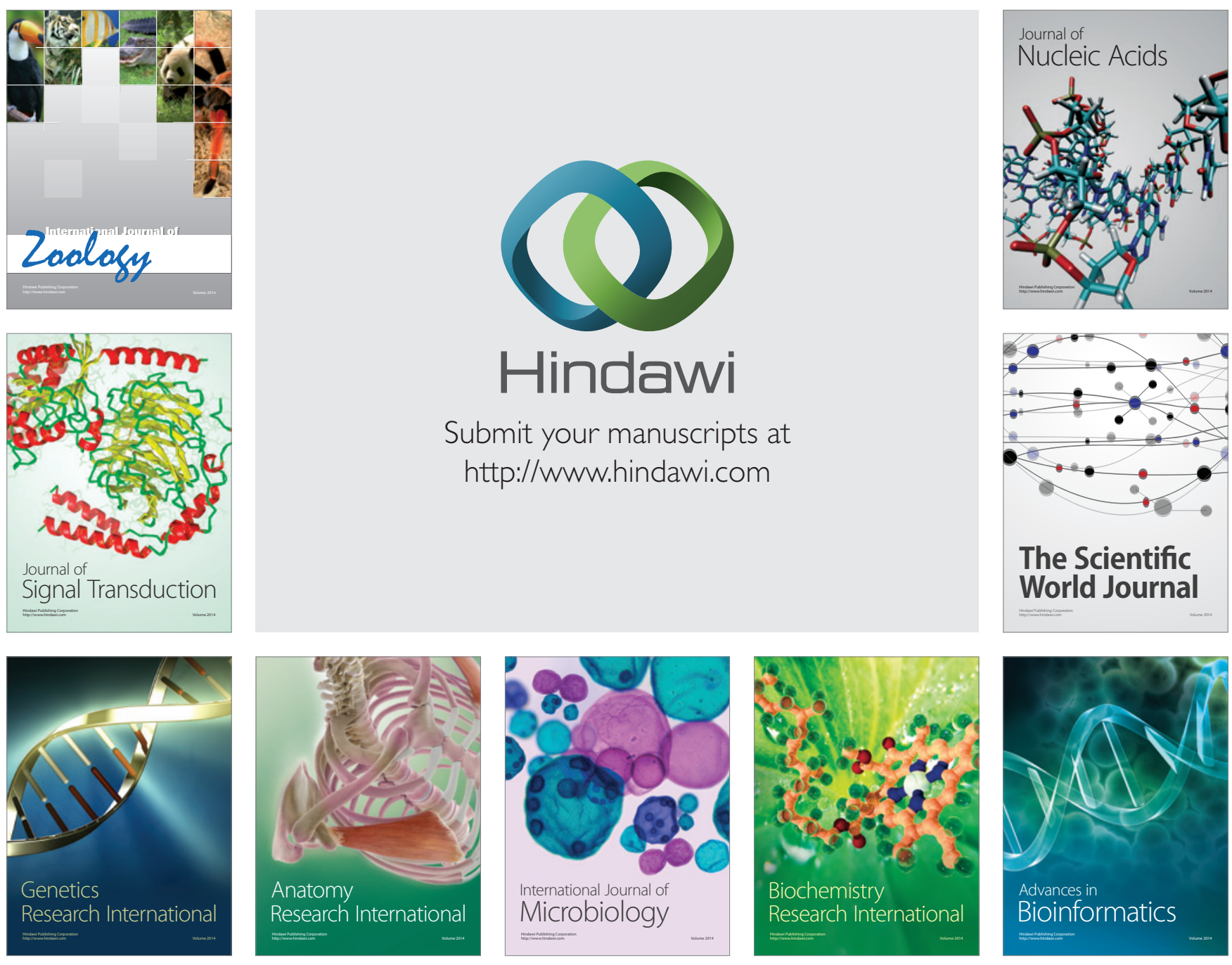

The Scientific World Journal
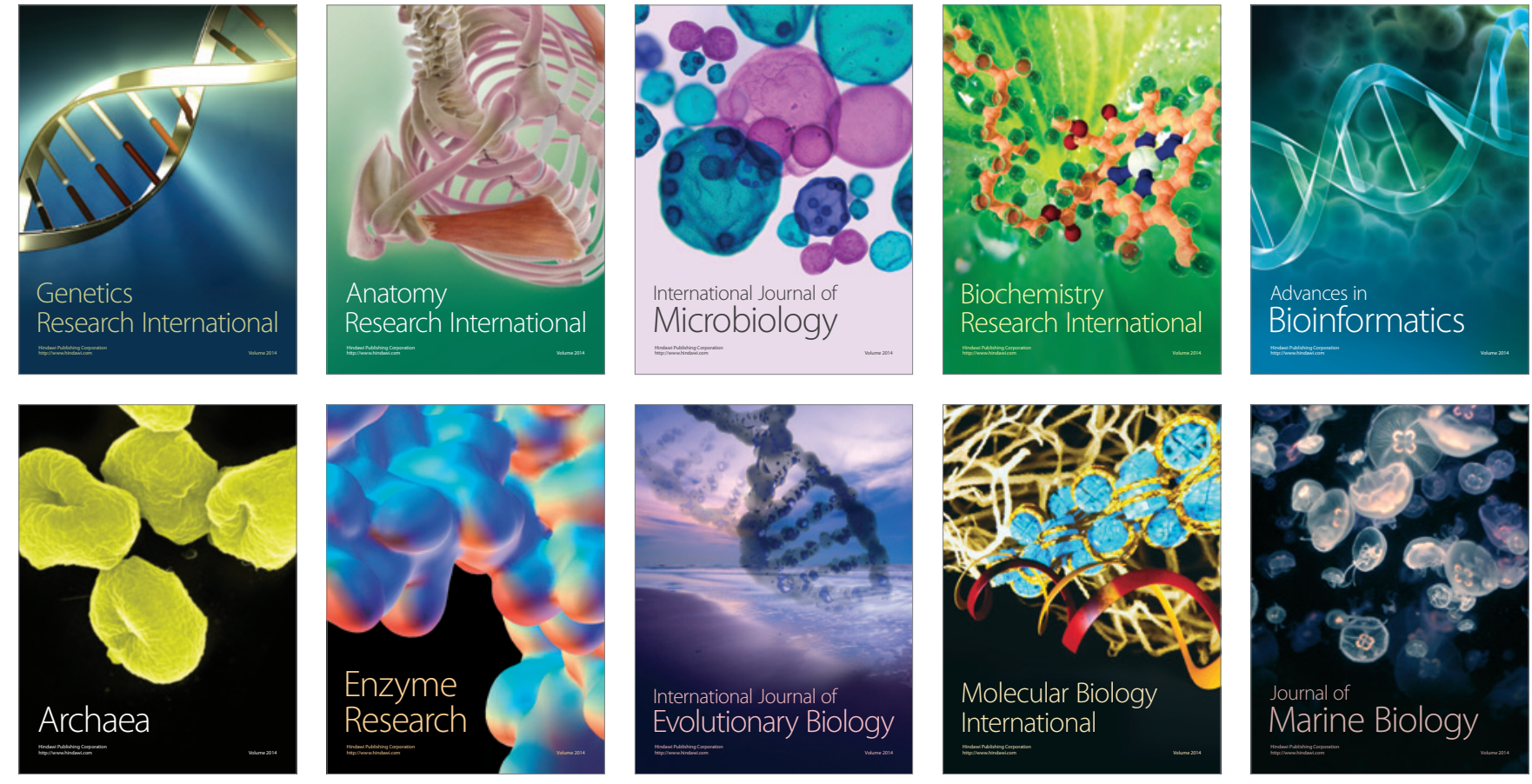